\title{
Computer simulation of channel processes
}

\author{
B Shokirov ${ }^{*}$, B Norkulov, Kh Nishanbaev, M Khurazbaev and B Nazarov \\ Tashkent Institute of Irrigation and Agricultural Mechanization Engineers, Waterpower exploitation \\ and pumping stations, 100000, Tashkent, Kara-Niyaziy str.
}

\begin{abstract}
The article discusses the results of numerical studies of flow movement with a sharp change in the channel parameters. The numerical study of the flow in the channels and rivers creates the possibility of a multivariate forecast of channel processes, rivers, and requires minimal expenditures. The purpose of the study is to determine the main objectives and directions of research in the area under consideration. A mathematical model and a computer program have been developed that allow solving a wide range of tasks for modelling currents in the channels of various difficulties, taking into account daily regulation. This makes it possible to identify and proactively take measures, such as: determining the time to reach the flow along the channel; the establishment of water volume flow in an arbitrary channel; taking emergency measures to regulate the incoming residual volume of water after its termination into the system, in the event of an accident at pumping stations; identification of the nature and direction of channel processes; prevention of undermining of supports and damage to power lines passing through the channel, and many other engineering tasks. The developed tested mathematical model allows in real conditions and in real time to help the operational services of large channels in the operational management of actions, in emergency situations, and the choice of the most effective, at any point in time, measures to minimize the consequences. Analysis of the results of many researchers has created the opportunity for the authors of this article to conclude that the above system of hydrodynamic equations is applicable in mathematical modelling of motion, taking into account the transverse circulation of the flow.
\end{abstract}

\section{Introduction}

The aim of the study is to create a mathematical model that allows to obtain predictive data on: the ongoing channel processes in the channels, using the necessary data on the physical and geographical conditions in water intake section; climate; hydrological regime; sediment composition; regime of liquid and solid runoff; flow dynamics; turbidity of planned coastal and deep deformations in the channel; identifying the condition of applicability of the existing systems of unsteady flow equations of water in the formation of transverse circulation.

The rivers of the Aral Sea basin are especially distinguished from many rivers in the world by transport and a high concentration of sediment. The fractional composition of

\footnotetext{
* Corresponding author: dr.bazarov@ mail.ru
} 
these sediments varies in wide ranges. A striking example is the dynamics of the fractional composition of the middle course of the Amudarya River [11] (Table 1).

The measured average daily turbidity of water in the Amudarya River, in recent years of observations, is $5.12 \mathrm{~kg} / \mathrm{m}^{3}$. The minimum annual turbidity, in recent years, has been recorded, and in the average long-term annual flow of suspended sediments of the Amudarya, at Cape Pulizindan, in the area of the non-dam intake into the Karshi Main Channel, is 23 million tons. The highest sediment discharge rate can reach 95,000 kg/s. The average annual consumption of suspended sediment for a long-term period is $6500 \mathrm{~kg} / \mathrm{s}$. The annual sediment discharge for the long-term period is 210,000 thousand tons or 168 million $\mathrm{m}^{3}$, which gives an average washout from the basin area of 650 tons $/ \mathrm{km}^{2}$ or 520 $\mathrm{m}^{3} / \mathrm{km}^{2}[12]$.

Table 1. Fractional composition of suspended sediment of the Amudarya River in the area of the nondam intake into the Karshi Main channel.

\begin{tabular}{|c|c|c|c|c|c|c|c|}
\hline \multirow[t]{2}{*}{ Content } & \multirow[t]{2}{*}{ Distribution } & \multicolumn{6}{|c|}{ Fractional composition $(\mathrm{mm})$ and content by weight } \\
\hline & & $\begin{array}{l}1,0- \\
0,25\end{array}$ & $\begin{array}{l}0,25- \\
0,10\end{array}$ & $\begin{array}{l}0,10- \\
0,05\end{array}$ & $\begin{array}{l}0,05- \\
0,01\end{array}$ & $\begin{array}{l}0,01- \\
0,005\end{array}$ & $<0,005$ \\
\hline \multirow[t]{5}{*}{ Large } & 1 & 1,0 & 13,7 & 31,0 & 32,1 & 15,0 & 7,2 \\
\hline & 2 & 1,3 & 13,8 & 31,5 & 31,0 & 10,0 & 13,4 \\
\hline & 3 & 1,2 & 13,5 & 30,1 & 31,0 & 11,0 & 14,2 \\
\hline & 4 & 3,0 & 14,2 & 29,4 & 28,7 & 14,0 & 10,7 \\
\hline & Average & 1,5 & 13,8 & 30,5 & 30,7 & 12,5 & 11,0 \\
\hline \multirow[t]{5}{*}{ Average } & 1 & 0,8 & 3,5 & 19,4 & 24,8 & 35,8 & 10,7 \\
\hline & 2 & 1,3 & 3,6 & 18,9 & 30,1 & 28,0 & 19,1 \\
\hline & 3 & 1,2 & 2,8 & 20,1 & 27,6 & 29,8 & 18,5 \\
\hline & 4 & 1,8 & 0,9 & 8,1 & 20,2 & 42,1 & 26,5 \\
\hline & Average & 1,3 & 2,7 & 16,6 & 26,7 & 33,9 & 18,8 \\
\hline \multirow[t]{5}{*}{ Small } & 1 & 0,5 & 1,6 & 12,0 & 7,2 & 40,3 & 38,4 \\
\hline & 2 & 0,5 & 0,6 & 3,5 & 13,0 & 45,8 & 37,6 \\
\hline & 3 & 0,5 & 1,0 & 5,9 & 12,1 & 45,6 & 35,9 \\
\hline & 4 & 0,3 & 1,8 & 4,5 & 7,8 & 41,8 & 43,8 \\
\hline & Average & 0,5 & 1,1 & 6,5 & 10,0 & 43,0 & 38,9 \\
\hline
\end{tabular}

Since these sediments entering the channels and creates great difficulties during the water intake, measures are being taken to sediment them to the pumping stations or to the consumer. For this purpose, various engineering structures are taken in the entrance of the channel, such as: thresholds that prevent the flow of sediment into the channel of the channel; creation of an artificial transverse circulation in the area of the non-dam intake, ensuring the change in direction of the sediment in the opposite direction from the intake; sedimentation tanks for sedimentation of sediment in a certain part of the channel and other structures. Finding the optimal size of these structures is always relevant and in demand in the production of hydraulic engineering and hydropower practice [13-17].

\section{Method}

A detailed comparison of the results of numerical and laboratory modelling of the flow in open channels, with a sharp increase in the width of the channel, characteristics the movement of water flow behind deaf dams, was conducted by V.M. Lyatkherom and A.N. Militeev $[1,2,18]$. The results of the numerical experiments of the aforementioned 
researchers, which are of fundamental importance, in comparison with the data of laboratory experiments of B.A. Friedman [6], are presented in Figure 1.1.

In earlier works, it was noted that in numerical modeling of currents in such channels, using the full hydrodynamic equations of water flow, taking into account convective terms, behind the ledge, a whirlpool appears, observed in physical experiments and in natural conditions; if, however, to use simplified equations with rejected convective terms, the flow spreads immediately behind the ledge, without forming a whirlpool. In addition, this is confirmed by the results of M. Abbott's numerical experiments [4], presented in Figure 1.2. Note that in this work the impossibility of the realization of hydraulic phenomena, described by Saint-Venant equations, without taking into account the friction between the jets in terms of the stationary whirlpool, corresponding to the Cartwelisville theorem [5], is not noted.

According to theory G.V. Stefanovich [7], which compared a large number of results of numerical and laboratory experiments by various authors (including his own experiments), for sufficiently large flow depths, the relationship between the relative length of the whirlpool and the parameter is broken even at very small Froude numbers. G.V. Stefanovich explains this violation by the necessity of taking into account, in this case, a mathematical model of the forces of turbulent viscosity. Another factor that can affect the whirlpool length is the presence of pulsations (inlet turbulence) in the entrance chamber. In the numerical experiments of V.M. Lyahter and A.N. Militeeva, there were no ripples of hydrodynamic quantities in the entrance section. According to the results of our research, at shallow water depths at the entrance prismatic section of the channel, the input pulsations attenuate, and at greater depths of the flow they do not attenuate [6].

Figures 1.3 and 1.4 show the results of numerical and physical experiments conducted in the design of real objects and in which water flows were studied in areas with a sharp change in the channel width.

In the experiments presented in Figure 1.4, the flow of water was studied in a fragment of the Lower-Kamsky reservoir, in a zone with complex bottom relief [8]. Studies were conducted both by numerical methods and on the air pressure model. A large coincidence was obtained in which the values of the water velocity coincided with the parameters of the whirlpool zones.

In the experiments presented in Figure 1.5, the flow of water at the bridge over the river was studied [8]. Studies were conducted both by numerical methods and on the hydraulic model. The diagrams of the longitudinal velocity obtained by both methods are close to each other.

A detailed study of the applicability of the planned Saint-Venant equations for highly unsteady flows, in areas of significant change in the shape of the channel, was carried out in [9]. A channel of rectangular cross section without a bottom slope with a sharp fivefold expansion in the plan was considered. A fast-opening shutter was installed in the extension. Before the shutter opened on a narrow section of the channel, the depth exceeded the depth on a wide section. When opening the shutter, a breakthrough waves occurred; during its propagation over the region, measurements of the hydrodynamic parameters of the flow were carried out. Figures 1.6-1.8 show the depths of isolines corresponding to the same point in time, obtained in a numerical experiment, photographs of the water surface, and graphs of the calculated depth in the wide part of the channel on the axis of symmetry of the flow are plotted. For comparison, the graphs are plotted depth values at several points, measured during the experiment.

The results of numerical experiments using the models of AN. Militeeva and B.L. Istorik, well coincided with the physical experiments of G.L. Mažbitsa [10]. Significant deviations observed in the period of time immediately following the arrival of the wave, G.L. Majbits refers exclusively to the influence of the curvature of the jets and the resulting 
deviation from hydrostatic pressure [10]. We point out another possible reason for such a deviation - the impact of the process of opening the shutter.

After a relatively short time interval after the arrival of the wave, the depths obtained in the physical and numerical experiments are close to each other with an accuracy of $5-10 \%$. Judging by the comparison of the calculated fields of isolines of the free surface of water and photographs of a physical experiment, the qualitative picture of the phenomenon, including the location of the inverted burs, turning into oblique hydraulic jumps, is almost the same. The greatest difference at all points in time, the point closest to the end point (Fig. 1.6 - 1.8), located at a distance of $1 \mathrm{~m}$ from the river bed extension, is apparently explained by the pressure deviation in this zone from the hydrostatic one.

The point dropped out in Figure 1.8, located at a distance of $8 \mathrm{~m}$ from the riverbed extension, apparently should not be taken into account, since the marked increase in the level is due to the reflection of the wave from the wall of the tray that was not specified in the numerical model.

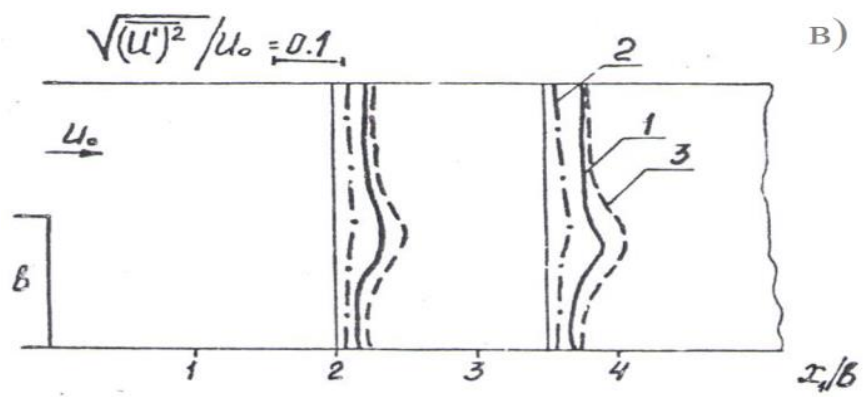

1 - calculation on a frequent grid, 2 - calculation on a rare grid, 3 - experiments by B.A. Friedman

Fig. 1.1. Comparison of the results of the physical (solid line) and numerical experiments on the study of flow with a sharp change in the width of the channel.
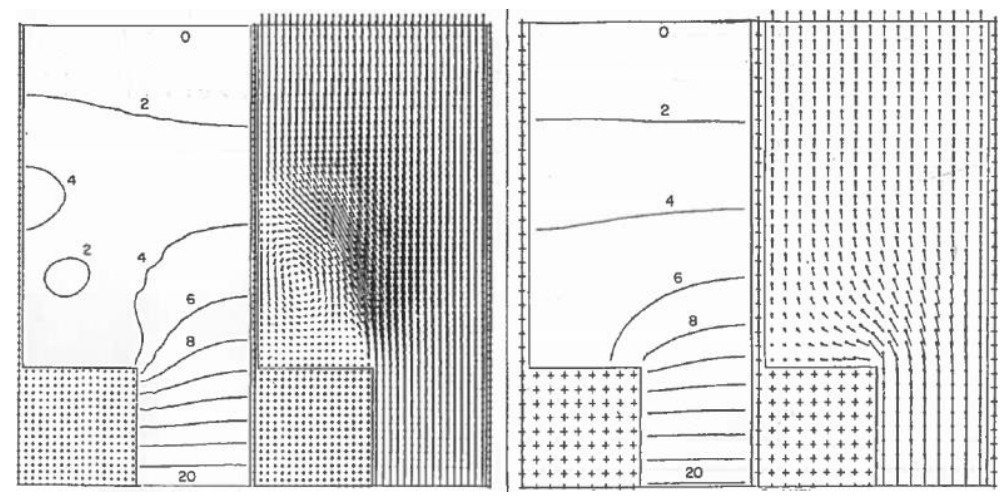

Figure 1.2. A numerical solution to the problem of sudden flow expansion using the two-dimensional Saint-Venant equations with and without convective terms [4]. 


\section{FORM-2019}

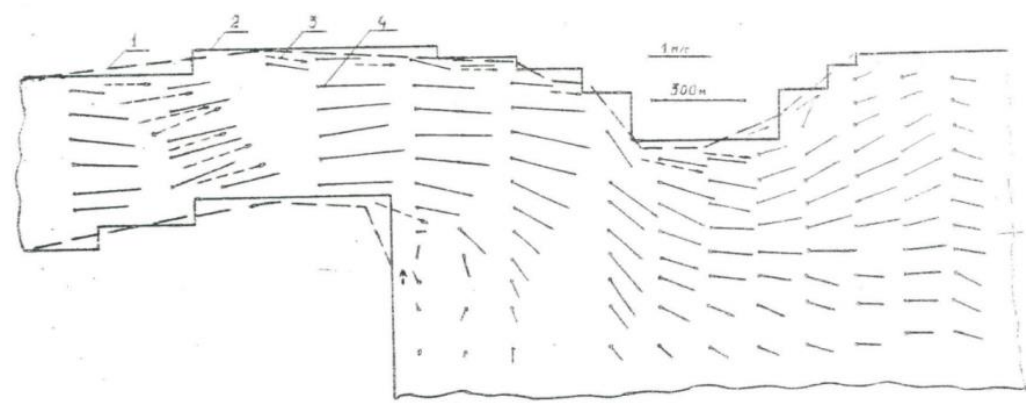

Figure 1.3. Plan of the currents in the section of the Kama River in the Lower Kama reservoir [9] .1 the boundary of the reservoir fragment on the model;

2 - calculated boundary; 3 - velocity vectors measured on the model (experiments of A.D. Khalturin and V.T. Silkin); 4 - calculated velocity vectors.

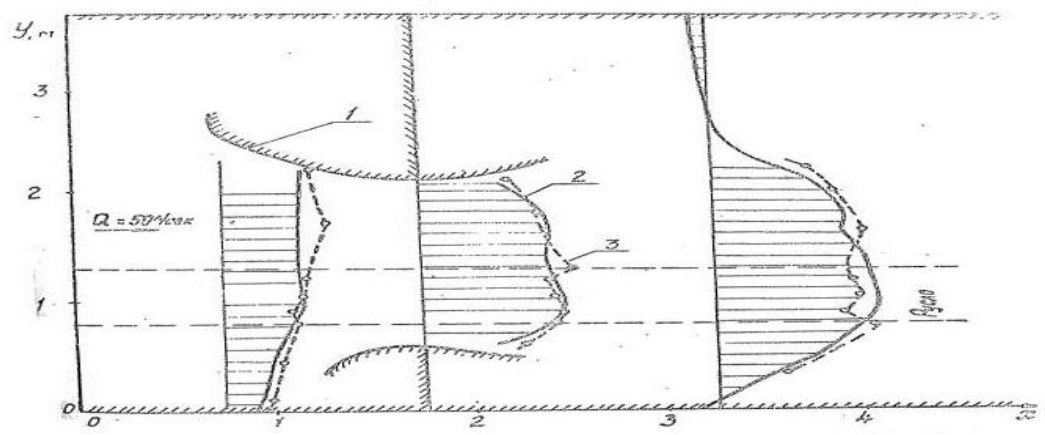

Figure 1.4. Diagrams of the longitudinal flow velocity at the bridge junction (on the model scale) [10]. The average slope of the bottom is $i_{x}=0.001$. Roughness factor $n=0,013.1-$ damp; 2 calculated diagram of the velocity modulus, 3 - observed on the model diagram.
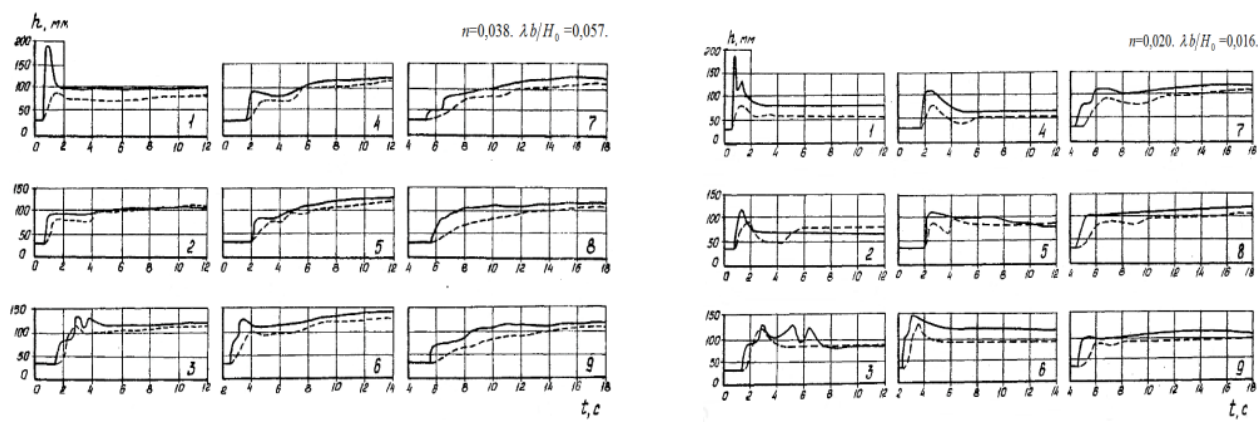

Figure 1.5. Comparison of the results of the physical (solid line) and numerical (dashed) experiments on the propagation of a spout wave through a channel with a fivefold expansion [10]. (The numerical experiment was performed according to the program of A.N. Militeev). Width: narrow part $-1 \mathrm{~m}$. Wide part $5 \mathrm{~m}$. Initial depth: in the narrow part $\mathrm{H}_{0}=0.6 \mathrm{~m}$, in the wide part $\mathrm{h}_{0}=0.03 \mathrm{~m}$. 

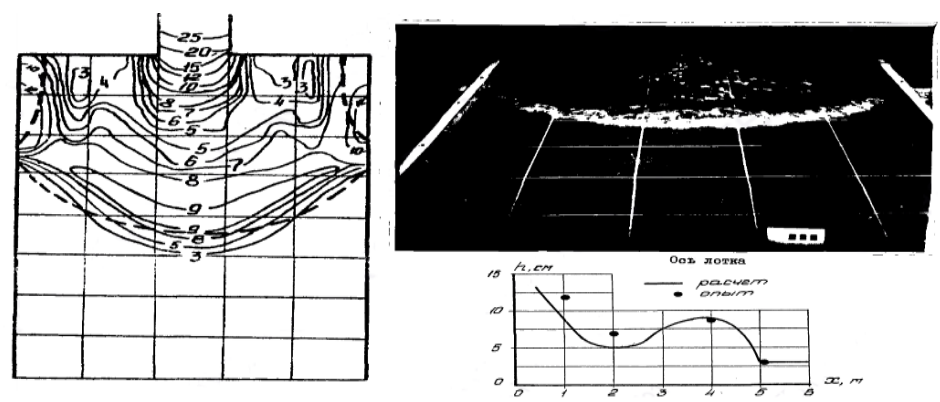

Figure 1.6. Comparison of the results of physical and numerical experiments on the propagation of a spout wave through a channel with a fivefold extension [9] (the numerical experiment was performed according to the program of B.L. Istorik). Time: after $2 \mathrm{~s}$. after opening the shutter. Width: narrow part $-1 \mathrm{~m}$, wide part $-5 \mathrm{~m}$. Initial depth: in the narrow part $\mathrm{H}_{0}=0.6 \mathrm{~m}$, in the wide part $\mathrm{h}_{0}=0.03 \mathrm{~m}$. $\mathrm{N}=0.012$.
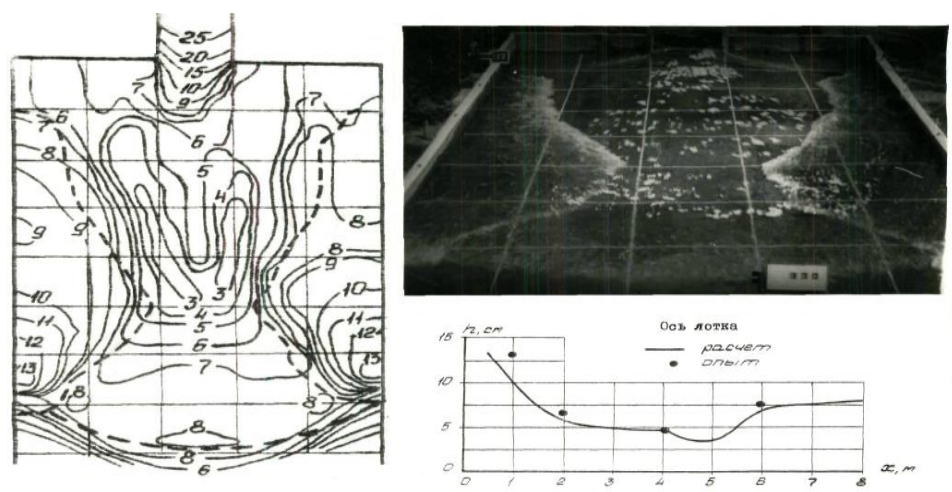

Figure 1.7. Comparison of the results of physical and numerical experiments on the propagation of a spout wave through a channel with a fivefold extension [9] (the numerical experiment was performed according to the program of B. L. Istorik). Time: after $4 \mathrm{~s}$. after opening the shutter. Width: narrow part - $1 \mathrm{~m}$, wide part $-5 \mathrm{~m}$. Initial depth: in the narrow part $\mathrm{H}_{0}=0.6 \mathrm{~m}$, in the wide part $\mathrm{h}_{0}=0.03 \mathrm{~m}$. $\mathrm{N}=0.012$.
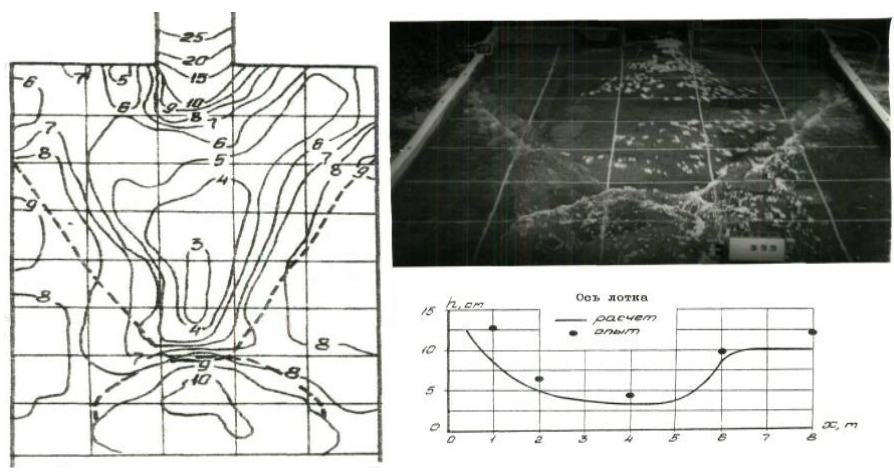

Figure 1.8. Comparison of the results of physical and numerical experiments on the propagation of an ebb wave through a channel with a fivefold extension [10] (the numerical experiment was performed according to the program of B. L. Historian). Time: 8 seconds after the shutter opens. 
Width: narrow part - $1 \mathrm{~m}$, wide part - $5 \mathrm{~m}$. Initial depth: in the narrow part $\mathrm{H}_{0}=0.6 \mathrm{~m}$, in the wide part $\mathrm{h}_{0}=0.03 \mathrm{~m} . \mathrm{N}=0.012$.

\section{Results and discussion}

The authors of this paper and D.R. Bazarov [11] investigated the effect of length increments on the results of numerical experiments. According to the results of numerical studies, graphs of the change in time of the longitudinal component of the velocity following a sudden double expansion of the channel are presented. These graphs and the above results, clearly demonstrated a picture of the behaviour of water velocity in the area below the sudden expansion. The flow all the time was non-stationary and had the character of stationary pulsations, and, the finer the grid, the richer was the spectrum of these pulsations. The time step in the calculations has always been much shorter than the minimum period of the pulsations; therefore, these pulsations are not associated with the difference oscillations that can occur when the central differences are approximated. Since the flow is strongly elongated along the longitudinal direction, then for the main series of calculations, a large ratio of steps was chosen.

According to the authors of the above studies and this article: the pulsations on different grids differ significantly from each other, the average values of the velocities are close, i.e. the solution for mean values converges well; it has been proved that the pulsations are a property of the original St. Venant equations.

The analysis of the above works to the authors of this work allowed to state the fact that a two-dimensional system of hydrodynamic equations, allowing to calculate the deformation of the channels of the channels, can be taken as follows:

$$
\begin{aligned}
& \frac{\partial h S}{\partial t}+\frac{\partial U S h}{\partial x}+\frac{\partial V S h}{\partial y}=-K\left(S-S_{*}\right) \\
& (1-\mathrm{p}) \frac{\partial \mathrm{Z}_{\mathrm{b}}}{\partial \mathrm{t}}=K\left(S-S_{*}\right)+\frac{\partial}{\partial x} D \frac{\partial Z_{b}}{\partial x}+\frac{\partial}{\partial y} D \frac{\partial Z_{b}}{\partial y} ; \\
& K= \begin{cases}\alpha U_{*}+(1-\alpha) W, & U_{*} \geq W 0 \leq \alpha<1 ; \\
W, & U_{*} \leq W\end{cases} \\
& D=\beta \tilde{S} h W \\
& S_{*}=\alpha_{1} \frac{\lambda \rho}{2 \rho_{s}} \frac{\left.|\vec{U}|-U_{N}\right)^{2}}{g h}\left(\frac{0.13}{\operatorname{tg} \varphi}+0.01 \frac{|\vec{U}|}{W}\right), \lambda=2 g n^{2} h^{-1 / 3}
\end{aligned}
$$

where, $t$ - time; $h$ - flow depth; $U, V$ - axis velocity components $X$ and $Y ;|\vec{U}|=\sqrt{U^{2}+V^{2}}$; $S$ - volume concentration of sediment particles in the stream; $S$ - the equilibrium volume concentration of particles (saturation concentration), taken according to the modified Bagnold formula; $K$ - the rate of intensity of the vertical exchange of sediment between the bottom and the flow; $p$ - soil porosity (ratio of pore volume to total soil volume with pores); $\rho_{s}, \rho$ - the density of soil and water, respectively; $\varphi$ - angle of internal friction of the soil; 
$W$ - hydraulic soil size; $U_{*}$ - динамическая скорость; $|\vec{U}|, U_{N}-$ the module of the average vertical flow velocity and non-shear velocity, respectively; $\lambda$ - coefficient of hydraulic friction, calculated by the Manning formula; $\mathrm{n}$ - roughness coefficient.

In the calculations, the non-shifting velocity was taken according to the formula of V.N. Goncharova, T.E. Mirtskhulava, which, taking into account the standard values of the coefficients, has two formally equivalent types of record:

$$
\begin{gathered}
U_{N}=\lg \frac{8.8 h}{d_{90}} \sqrt{\frac{2}{3.5}\left[\left(\rho_{s}-\rho\right) g d_{50}+1.25 C_{y}^{H}\right]} \\
U_{N}=0.18 \sqrt{\frac{2}{3.5 \lambda}\left[\left(\rho_{s}-\rho\right) g d_{50}+1.25 C_{y}^{H}\right]},
\end{gathered}
$$

where, $C_{y}^{H}-$ soil adhesion in $\mathrm{t} / \mathrm{m}^{2} ; d_{50}$ - average particle diameter of soil; $d_{90}-90 \%$ diameter of soil particles.

In the calculation of the diffusion coefficient (7) used for the three variants of the formulas $\tilde{S}$ :

a) by total equilibrium concentration of sediment and suspended sediment:

$$
\widetilde{S}=S_{*}
$$

b) by bottom equilibrium concentration:

$$
\tilde{S}=\alpha_{1} \frac{\lambda \rho}{2 \rho_{s}} \frac{\left(|\vec{U}|-U_{N}\right)^{2} \cdot 0.13}{g h \operatorname{tg} \varphi}
$$

c) by bottom concentration "without square":

$$
\tilde{S}=\alpha_{1} \frac{\lambda \rho}{2 \rho_{s}} \frac{\left(|\vec{U}|-U_{N}\right)|\vec{U}| \cdot 0.13}{g h \operatorname{tg} \varphi},
$$

The first resets the bottom surface as the initial conditions $Z(x, y, 0)$ and corresponding instantaneous speed fields $\vec{U}(x, y, 0)$, depths $h(x, y, 0)$ and concentration $S(x, y, 0)$.

\section{Conclusion}

Thus, the results of the analysis of the above studies allow the authors to make a conclusion about the applicability of the numerical model composed of shallow water equations, the vector momentum conservation equation and the scalar mass conservation equation when describing a flow with circulation zones, which is typical of a sharp expansion of the channel. In this case, the solution pulsates around a certain mean value, and the average length of the circulation zone following a sudden expansion of the open flow agrees well with laboratory experiments [3]. 
The authors of this scientific work express their gratitude for the opportunity to conduct research in the field of personal science and teaching technical sciences, and the profession of prof. Dilshod Rayimovich Bazarov. The authors consider it their duty to particularly note the great assistance of the administration of the Tashkent Institute of Irrigation and Agricultural Mechanization Engineers, represented by the rector - Doctor of Economics, Professor Uktam Pardaevich Umurzakov, who created a good chance for writing this scientific work and provided financial support before publication.

\section{References}

1. Lyather V.M. Militeev A.N. Hydraulic research by numerical methods. Water Resources, No. 3, (1981)

2. Militeev A.N. Solving problems of hydraulics of small ponds and pools of waterworks using numerical methods. Thesis for the degree of doctor of technical sciences. M., (1982)

3. Bakiev R.M. Kakhkharov U. Hydraulics of the flow, constrained by deaf transverse dams on rivers with double-sided dam. Hydrotechnics, No. 1, (2016)

4. Abbot M. Hydraulics open flow (translated from English.). M.: Energoatomizdat, pp. 272, (1983)

5. Kartvelishvilli N.A. Flows in non-deformed channels. Hydrometeoizdat, L.: (1973)

6. Friedman B.A. Turbulence of water flows - L.: Gidrometeoizdat, (1991)

7. Stefanovich G.V. Planned expansion of the flow in the downstream of the hydro and water areas. News All-Russian Research Institute of Hydraulic Engineering.

8. Militeev A.N., Shkolnikov S.Y. Numerical methods for studying flow patterns in channels with complex bottom relief. Water Resources, No. 3, (1981)

9. Belikov V.V. Improving the methods and technologies of applied numerical modeling in open flow hydraulics. Thesis for the degree doctor of technical sciences. M. (2005);

10. Majbitz G.L. Experimental justification of methods for modeling highly unsteady separated flows in open channels. Thesis for the degree of candidate of technical sciences. M., (1984)

11. Bazarov D.R. Thesis for the degree of Doctor of Technical Sciences. Scientific substantiation of new numerical methods for calculating riverbed deformations of rivers whose beds are composed of easily eroded soils, Specialty 05.23.16 - hydraulics and engineering hydrology, M: pp. 249, (2000)

12. Bazarov D.R. "Development of measures to improve the operating conditions of the dam-free intake". Reg. No. 18925/2016, Ministry of Agriculture of the Republic of Uzbekistan, pp. 85, (Tashkent 2016)

13. Velikanov M.A. Channel process (Fundamentals of the theory). State Publishing House Phys-Mat. Literature. M. pp. 395, (1958)

14. Scientific and Technical Report of the SANIIRI Channels Department for 1969-1970 on the work "Collection, systematization and analysis of research materials and methods of combating this phenomenon on the Amudarya River", (Tashkent, 1970)

15. The plan of measures for the repair and restoration of protective and regulatory structures of the lower reaches of the Amudarya River in 2011 G. Beruni., P. (Uzbekistan, 2010)

16. Report of the Deputy Minister of Agriculture and Water Resources of the Republic of Uzbekistan Sh.R. Khamraeva at the regional conference devoted to the preparation for the 6th World Water Forum: “Uzbekistan's water industry on the way to overcoming destabilizing factors through the introduction of innovations and international water law", (Tashkent, 12-13 May, 2011) 
17. National Report of the Republic of Uzbekistan in the framework of the UNEP program to promote and assist developing countries in implementing the Johannesburg plan for the implementation of the goal "Action Plans for Integrated Water Resources Management and Water Conservation" Tashkent, pp. 25, (2005)

18. Militeev A.N. Solving problems of hydraulics of small ponds and pools of waterworks using numerical methods. Thesis for the degree of Doctor of Technical Sciences, M. pp. 307, (1982) 